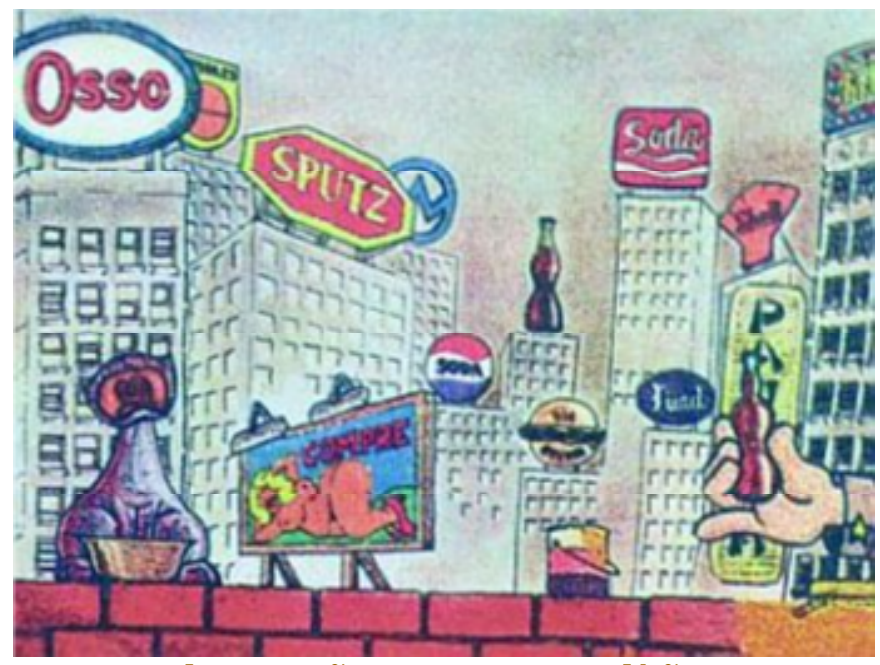

Ilustração Marcos Magalhães

\title{
As metáforas e o cinema de animação: uma análise do filme Meow!
}

\section{Maurício Silva Gino \\ Ronaldo Luiz Nagem \\ José Tavares de Barros}

Maurício Silva Gino é professor Mestre (Escola de Design da UEMG e UNI-BH); Ronaldo Luiz Nagem é professor Doutor (Centro Federal de Educação Tecnológica de Minas Gerais - CEFET-MG); José Tavares de Barros é professor Doutor (Escola de Belas Artes da UFMG).

\section{Resumo}

Este artigo tem por objetivo apresentar as intenções e os significados atribuídos por Marcos Magalhães às metáforas presentes no filme Meow!Por meio de entrevista semiestruturada, registraram-se as intenções e os significados atribuídos pelo produtor para cada cena ou personagem. Os resultados foram analisados e discutidos tendo como suporte teórico as proposições de Lakoff \& Johnson(1), dentre outros. A conclusão a que se chega é que o autor seleciona alguns aspectos de nossas experiências culturais, ao mesmo tempo em que simplesmente desconsidera outros, o que faz do seu filme o veículo de uma realidade metafórica. Nesse sentido, a metáfora 
apresenta-se como um recurso de fundamental importância para a expressão artística de Marcos Magalhães que, por meio do filme, expõe sua visão de mundo e seus posicionamentos político e ideológico.

Palavras-chave:

metáforas, analogias,

animação

cinematográfica.

Num mundo em que a comunicação tem assumido as mais diversas formas e que a imagem tem desempenhado um importante papel como mediadora de idéias, torna-se fundamental estudar os diversos meios como sistemas capazes de determinar novas formas de linguagem.

Nesse sentido, buscamos avaliar algumas estratégias adotadas pelo cinema de animação no desenvolvimento de uma linguagem própria que acreditamos ser essencialmente metafórica. Para isso, analisamos o filme Meow!, de Marcos Magalhães (1981), do ponto de vista de sua estruturação metafórica.

Nosso método de análise baseou-se em entrevista semiestruturada realizada com o autor do filme, o que permitiu identificar com bastante precisão suas intenções relativas às metáforas veiculadas. Além disso, as proposições de Lakoff e Johnson mostraram-se muito apropriadas ao tipo de trabalho ao qual nos propúnhamos, fornecendo-nos portanto uma importante base teórica e metodológica para análise.

Antes, porém, iniciamos com uma necessária e minuciosa descrição do filme, o que visa a possibilitar uma contextualização de nossa análise por parte do leitor.

\section{Descrição do filme}

Meow!(2) é um curta-metragem em animação com oito minutos de duração, produzido em 1981 por Marcos Magalhães e pela EMBRAF ILME .

O cenário inicial do filme é um local que se parece com a periferia de uma grande cidade, onde se inicia grande panorâmica acompanhada por música. A câmera mostra um grande muro em primeiro plano, com construções não muito altas ao fundo. De repente, a explosão de uma daquelas casas marca o início dos grandes prédios da cidade. O movimento de câmera prossegue e ouve-se o plin-plin da Rede Globo, vindo dos apartamentos. No alto dos edifícios, vêem-se vários anúncios luminosos e ouvem-se também as buzinas de um trânsito caótico. Em seguida, as grandes construções dão lugar a uma favela por detrás do muro. Ouve-se a sirene de um carro de polícia e 
várias pessoas pulam o muro para fugir. A panorâmica termina quando um gato, sentado no muro, ocupa o centro da tela. A música é interrompida bruscamente e a imagem se fecha no gato que mia calmamente.

Após o miado do gato, aparece uma mão com a manga do paletó verde-amarelada que lhe acaricia a cabeça e em seguida coloca um prato sobre o muro, servindo-lhe leite. 0 som do leite sendo servido é semelhante ao de uma torneira enchendo um balde de alumínio. O gato toma todo o leite e mia novamente pedindo mais. O leite é servido por quatro vezes e o gato não se satisfaz, sempre miando querendo mais. Ao ser servido novamente, o leite se esgota e caem apenas duas gotas no prato do gato que, insatisfeito, mia insistentemente. A mão aparece novamente e bate violentamente com a garrafa vazia na cabeça do gato. Indiferente à agressão sofrida, o gato mais uma vez mia, irritante e incansavelmente. A mão aparece para dar nova garrafada na cabeça do gato, mas é impedida por outra mão com a manga do paletó nas cores vermelha e branca. As duas mãos iniciam uma luta. Aparecem sapatos e garrafas voando, nuvens, estrelas. Ao final da briga, a última estrela que se apaga é verde-amarelada.

o gato mia brevemente. A nova mão, com a manga vermelho-ebranca, troca o antigo prato de leite por um vermelho com uma faixa branca, como na marca da Coca-Cola. Em seguida, acaricia a cabeça do gato, que mia pedindo leite. Ouve-se uma garrafa sendo destampada. A mão aparece com uma garrafa preta e de linhas curvas e serve seu conteúdo ao gato. O som agora é semelhante ao de um borbulhante refrigerante sendo servido em um copo. O gato experimenta a nova bebida, mas não gosta e cospe. Em seguida, mia insistentemente, quando vários anúncios da nova bebida, a Soda-cólica, são colocados ao seu redor. O gato mais uma vez mia insistentemente. Um televisor é então colocado à sua frente, onde aparece uma gata muito sensual bebendo Soda-cólica e incentivando seu consumo. O gato não se convence com o comercial e mais uma vez mia incansavelmente. Leva então uma garrafada na cabeça e, ameaçado pela violência, toma todo o conteúdo oferecido. Em seguida, dá um arroto e mais Soda-cólica é colocada em seu prato sem que ele peça. O gato toma espontaneamente a Soda-cólica, dá outro arroto e mia pedindo mais. Novamente, oferecem-lhe Soda-cólica. O gato já toma a bebida com prazer e mia pedindo mais. Quando a mão vai lhe servir mais, a mão de manga verde-amarelada retorna, iniciando-se uma nova guerra. Mais uma vez, aparecem mísseis, nuvens, e estrelas. Ao final da briga, a última estrela que se apaga é vermelha e branca.

A mão com a manga verde-amarelada acaricia o gato e troca seu prato de Soda-cólica pelo antigo. O gato mia e o leite é servido. Começa então a tomar o leite, mas já não gosta mais 
da bebida e cospe. O gato dá um novo, insistente e irritante miado, acompanhado da legenda "MEOW". A mão aparece novamente e pega o gato pelo pescoço. A imagem é congelada e entram os créditos do filme.

\section{As metáforas e Meow!}

\subsection{A identificação de uma metáfora conceitual no filme}

Em nosso cotidiano, pensamos, agimos e nos expressamos por meio de conceitos estruturados metaforicamente. Em Meow! não é diferente: a partir da definição do tema "dominação cultural", desenvolve-se uma narrativa em torno do próprio conceito de CULTURA. Portanto, era intenção do autor falar sobre algo abstrato, sem uma forma definida, o que só é possível por meio da utilização de mecanismos metafóricos. Nesse sentido, para o autor, CULTURA é ALIMENTO, o que representa uma metáfora conceitual. Segundo Lakoff e Johnson,

os conceitos que assim se estruturam exigem uma definição metafórica, posto que eles não são suficiente e claramente definidos em seus próprios termos para satisfazer aos propósitos de nosso agir cotidiano(4).

Assim, CULTURA é ALIMENTO. E, dentro dessa metáfora, que é capaz de orientar toda a estrutura do filme, pode-se destacar um tipo ainda mais específico e coerente de alimento, a partir do qual afirma-se que CULTURA é BEBIDA. Considerada como bebida, a cultura possui algumas características importantes, dentre as quais são destacadas:

- cultura pode ser solicitada, como também pode ser servida;

- pode-se ingerir ou cuspir cultura;

- há possibilidade de que seja natural ou industrializada;

- cultura pode ter marca ou não;

- pode ser absorvida naturalmente pelo organismo, ou pode causar reações fisiológicas claras;

- consome-se a cultura com prazer, mas também pode ser consumida por imposição ou "empurrada goela abaixo";

- seu consumo pode se dar de forma espontânea, assim como pode ser introduzido por mecanismos externos;

- cultura pode gerar conflitos entre fornecedores ou agentes; 
- pode, ainda, ser nacional ou importada;

No entanto, CULTURA é apenas conceituada em termos de BEBIDA, não sendo portanto um exemplo de bebida. O veículo da metáfora (bebida) mantém pontos em comum com o conceito-alvo (cultura), mas deve guardar também suas diferenças.

Em sua metodologia de ensino com analogias - MECA, Nagem et al. definem o termo veículo de uma analogia, que é aplicável também à metáfora:

Quando falamos de veículo estamos nos referindo ao familiar
content, tal como definido por Curtis \& Reigeluth (1984). Ele é a
própria analogia, que proporciona a compreensão do objeto em
estudo. Esse termo é preferível a outros como analogue Thiele \&
Treagust (1995) ou bridge Dagher (1995), pela noça intuitiva de
movimento que facilita o entendimento do papel da analogia na
instrução, relacionada ao "levar o estudante ao conceito alvo"(5).

Por outro lado, conceito-alvo também é definido como sendo o domínio que se deseja ensinar. É propriamente o conceito desconhecido pelo aluno, que será explicado por meio de uma analogia ou de uma metáfora.

Ressalta-se que Nagem et al. estavam preocupados em propor uma metodologia de ensino baseada na analogia, mas os termos empregados para a análise de analogias com fins educacionais são também perfeitamente aplicáveis em análises de analogias ou metáforas em outros campos do conhecimento, tais como a ciência, a comunicação e as artes. Assim, temos no filme as seguintes diferenças entre veículo e alvo da metáfora, conforme o QUADRO 1:

\section{QUADRO 1: Diferenças entre veículo e alvo da metáfora CULTURA é BEBIDA,} presente em Meow!

\begin{tabular}{|c|c|}
\hline BEBIDA (veiculo da metafora) & CULTURA (alvo da metafora) \\
\hline $\begin{array}{l}\text { - Possui existência física, podendo } \\
\text { ser quente, gelada, àcida, amarga }\end{array}$ & $\begin{array}{l}\text { - A rigor não possui materialidade, } \\
\text { não podendo ser experimentada } \\
\text { pelos órgãos de sentido. }\end{array}$ \\
\hline - É liquida e é moldada pelo meio. & $\begin{array}{l}\text { - Näo possui estado físico e molda } \\
\text { o meio. }\end{array}$ \\
\hline $\begin{array}{l}\text { - Esgota-se e pode ser lambida até } \\
\text { a última gota. }\end{array}$ & $\begin{array}{l}\text { - E constantemente modíficada, } \\
\text { mas nunca se esgota. }\end{array}$ \\
\hline
\end{tabular}

A princípio, o autor coloca a cultura esgotando-se quando o gato lambe até a última gota do leite, o que pode parecer uma inconsistência no filme. No entanto, isto pode ser também interpretado como um momento de fragilidade por que passa a cultura natural, o que é aproveitado pelo agente externo, com 
bastante oportunismo, para impor uma nova ordem cultural. O autor parece querer destacar esse momento de fragilidade quando faz com que a cultura natural retorne com mais força, no final do filme.

A partir da definição de CULTURA como BEBIDA, podem-se classificar os diversos tipos de cultura existentes. Em Meow! encontram-se duas culturas bastante distintas, cujas diferenças são caracterizadas pelo QUADRO 2:

\section{QUADRO 2: Tipos de cultura representados pelo autor em Meow!}

\begin{tabular}{|c|c|}
\hline Cultura leite & Cultura Soda-Colica \\
\hline - Natural & - Industrializada \\
\hline - Näo possui marca & - Cultura de marca \\
\hline - Introduzida naturalmente & - Introduzida pela midia \\
\hline - Nacional & - Estrangeira \\
\hline - $\quad \dot{E}$ inicialmente solicitada & - É inicialmente imposta \\
\hline $\begin{array}{l}\text { - Näo provoca reações físiológicas } \\
\text { claras }\end{array}$ & - Causa arrotos \\
\hline - Não causa dependência & - Causa dependéncia \\
\hline
\end{tabular}

As diferenças entre cultura leite e cultura Soda-Cólica são responsáveis por todos os conflitos ao longo do filme.

\subsection{A formação de um sistema conceitual coerente}

De acordo com Lakoff e Johnson (6), as metáforas não são capazes de fornecer um entendimento completo, consistente e abrangente de todos os aspectos do seu conceito-alvo, quando consideradas isoladamente. No entanto, diversas metáforas podem se auxiliar mutuamente na compreensão dos diversos aspectos desse conceito-alvo, formando assim um sistema conceitual.

Mas, para que se crie um sistema conceitual, é importante a proposição de um conjunto de metáforas que se relacionem e mantenham coerência entre si. Tal conjunto, portanto, forma uma rede de metáforas capaz de estabelecer não apenas um conceito principal, mas todo um grupo de domínios a ele interligados.

Dessa forma, para que cultura seja definida como bebida, é necessário que alguém a consuma. Assim, a população que compartilha de uma determinada cultura tem que ser personificada. Criou-se então a metáfora PoPULAÇÃo é uma ENTIDADE, representada no filme antropomorficamente por um GATO. Como conseqüência, a população

- ingere bebidas;

- tem necessidades fisiológicas; 
- possui desejos e pode manifestá-los com insistência;

- pode sofrer pressões;

- tem suas preferências pessoais e suas necessidades moldáveis;

- pode aceitar passivamente as imposições externas.

Por outro lado, para que uma cultura-bebida esteja disponível para uma população-gato, é necessário que haja também um sistema ideológico que oriente as ações dessa população, a qual está inserida em determinada cultura. Para o autor, a mão com a manga de paletó verde-amarelada significa a sociedade brasileira, ou no contexto da época do filme, o Estado. Em oposição, a mão com a manga de paletó vermelha e branca representa o capitalismo norte-americano, ou qualquer outro agente imperialista impositor. Criou-se então em Meow! a metáfora: IDEOLOGIA é PROVEDOR. Assim temos,

- ideologia pode ser natural do país, ou pode ser estrangeira;

- pode fornecer as provisões básicas ou supérfluas para a população;

- ideologias podem brigar entre si;

- ideologias distintas não convivem pacificamente;

- elas se substituem e se modificam;

- podem morrer e ressurgir;

- ideologias podem ser autoritárias;

- também podem se impor por meio da força e do convencimento.

Conforme o QUADRO 3, encontram-se no filme os seguintes tipos de ideologias, com suas respectivas características:

QUADRO 3: Tipos de ideologia representados pelo autor em Meow!

\begin{tabular}{|c|c|}
\hline Ideologia manga de paleto verde-amarelada & Ideologia manga vermelha e branca \\
\hline - É própria da população & - 它 importada e introduzida \\
\hline - Fornece uma bebida natural & - Fornece uma bebida estrangeira \\
\hline - Tem a preferência natural da população & - Conquista a preferência da população \\
\hline - Apresenta momento de fragilidade & - Aproveita-se da fragilidade allheia \\
\hline - É autoritäria & - $\dot{E}$ também autoritária \\
\hline $\begin{array}{l}\text { - Dispõe apenas da força como } \\
\text { mecanismo de convencimento }\end{array}$ & $\begin{array}{l}\text { - Dispõe da força e de mecanismos } \\
\text { sofisticados de convencimento }\end{array}$ \\
\hline - Não consegue reintrocuzir sua bebida & - Conseque introduzir sua bebida \\
\hline
\end{tabular}




\title{
3.3. A formação da imagem por meio da metáfora
}

Retomando a proposição antropomórfica POPULAÇÃO é GATO, podese verificar como essa metáfora atua na criação da imagem relacionada ao conceito-alvo. Sabe-se que o gato é um animal doméstico e, em geral, com personalidade bastante forte. Porém, quando opta por colocar um felino aceitando passivamente as imposições externas, o que poderia ser conseguido mais facilmente com um cão, o autor parece querer enfatizar o efeito da dominação estrangeira. Portanto, utiliza-se de ironia, ao atribuir a um gato atitudes contrárias à sua natureza com o objetivo de valorizar o conceito que se pretende passar.

No entanto, isso não significa propriamente uma incoerência conceitual, mas um exagero permitido pelo cinema de animação. Essa opção feita pelo autor não diz respeito às características do gato, que é apenas o veículo de uma metáfora, mas permite que se construa a imagem da população como uma entidade. Para Sartre,

\begin{abstract}
diremos que a imagem é um ato que visa em sua corporeidade um objeto ausente ou inexistente, através de um conteúdo físico ou psíquico que não se dá em si mesmo, mas a título de "representante analógico" do objeto visado(7).
\end{abstract}

o problema é que a população não é apenas um objeto visado, mas algo muito mais amplo e abstrato. Sua definição de imagem como consciência é perfeitamente aplicável aqui, embora o conceito de população não esteja sendo formado a partir de analogias que estabeleçam relações comparativas explícitas, mas por meio de uma metáfora capaz de substituir um domínio por outro. Assim, de acordo com a FIGURA 1, forma-se a seguinte estrutura:

\section{FIGURA 1: Representação esquemática da formação da imagem por meio da metáfora}

Conceito-alvo

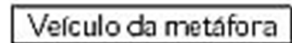

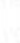

Conclusào

\begin{tabular}{|c|c|c|}
\hline População & Gato & Se até mesmo um gato, que tem \\
\hline $\begin{array}{l}\text { Caracteristica: a ser } \\
\text { Definida pela metáfora }\end{array}$ & $\begin{array}{l}\text { Caracteristica: } \\
\text { Personallidade forte }\end{array}$ & $\begin{array}{l}\text { então a população também as } \\
\text { aceitará passivamente. }\end{array}$ \\
\hline
\end{tabular}

É importante destacar que o simples fato de se falar de personalidade de um gato já significa que é atribuída a ele uma característica tipicamente humana, o que já constitui uma metáfora conceitual e antrópica (GATO é GENTE) . 


\subsection{A adoção de um sistema conceitual auxiliar}

Existe, ainda, em Meow! outro sistema conceitual independente que, no entanto, não constitui um conflito em relação ao sistema conceitual principal. Na prática, o tema do filme poderia ser exposto apenas com o sistema já identificado, mas um novo sistema é proposto com a finalidade de criar um contexto para a história, enfatizando, assim, as ações do filme.

Quando questionado sobre o significado do muro no filme, o autor respondeu que representa "a cidadania. A segurança. O status quo". Os três termos apresentados são relativamente distintos, mas a metáfora DIVISÃO SOCIAL = MURO pode ser proposta. Dessa forma,

- a posição em relação ao muro define a classe social;

- a perda da posição pode significar perda de cidadania;

- a possibilidade de perda de posição causa insegurança;

- a permanência é segura;

- é possível transitar entre as classes sociais;

- é possível permanecer entre as classes sociais;

- o que está além ou aquém do muro pode ser modificado;

- a divisão social pode ser pichada ou quebrada.

Essa metáfora permite que sejam apresentados alguns analogons, ou representantes analógicos de objetos, de acordo com os conceitos propostos por sartre:

é no terreno da percepção que eu quero fazer aparecer o rosto de Pierre, que quero "torná-lo presente". E, como não posso fazer surgir sua percepção diretamente, sirvo-me de uma certa matéria que age como um analogon, como um equivalente da percepção(8).

Vêem-se portanto prostitutas, pivetes e travestis pulando o muro que, segundo o autor do filme, representam os marginais, excluidos, sobreviventes. Mostra-se também a paisagem urbana que rapidamente se modifica por detrás do muro. Ainda de acordo com o autor, essa paisagem representa os efeitos globais da dominação cultural e econômica sobre as cidades dos países em desenvolvimento.

É importante destacar que, isoladamente, tais elementos gráficos não chegam a constituir metáforas porque não há uma 
substituição de domínios. Assim, para representar os excluídos da sociedade, o autor desenha os próprios excluídos, da mesma forma que representa as modificações urbanas desenhando essas alterações, ao longo do tempo e do espaço fílmicos. Trata-se, portanto, de representações que se referem diretamente às imagens que o autor busca formar no espectador.

Esses analogons estão presentes ao longo de todo o filme. Segundo o próprio autor, a gatinha do comercial significa a imagem ideal e sedutora da publicidade, e a TV é a ilusão feita para vender; recurso imprescindível para impor novas culturas. Portanto, ele se refere diretamente à publicidade e ao meio televisivo.

Nesse sentido e de acordo com Deleuze,

a metáfora se dá não por meio dos diversos elementos gráficos que compõem as cenas, mas pelo conjunto das ações que envolvem esses elementos no desenvolvimento da imagem-movimento(9).

\subsection{As metáforas por meio da animação cinematográfica}

Após a proposição de uma metáfora conceitual capaz de estruturar toda a narrativa, identificada como CULTURA é BEBIDA, o autor estabelece um sistema coerente ao longo do qual outras metáforas são mostradas. Toda essa rede de metáforas auxilia na estruturação do conceito de cultura com a finalidade de narrar ou mostrar como ocorre a dominação cultural, identificada pelo autor como sendo o próprio tema do filme.

Uma segunda metáfora conceitual, DIVISÃO SOCIAL é MURO, é proposta sem que haja uma relação direta com a metáfora principal CULTURA é BEBIDA. No entanto, sua proposição não é gratuita, uma vez que tem a finalidade de dar um contexto à história.

De certa forma, o autor seleciona alguns aspectos de nossas experiências culturais, ao mesmo tempo em que simplesmente desconsidera outros, o que faz de seu filme um veículo de uma realidade metafórica.

É importante destacar ainda que toda a narrativa se dá exclusivamente por meio de sons e imagens que se estruturam no tempo, recursos naturais do cinema e da animação. Não há, portanto, a necessidade do pronunciamento de uma palavra sequer, ao longo de todo o filme.

A metáfora, como um importante recurso de linguagem apropriado pela animação ao longo de sua história, é de fundamental importância para a expressão artística de Marcos Magalhães, 
que por meio desse filme expõe sua visão de mundo e seus posicionamentos político e ideológico daquele momento.

\section{Considerações finais}

Neste trabalho, buscamos apenas apresentar uma possível análise de um filme de curta metragem partindo do ponto de vista do discurso metafórico. Acreditamos, no entanto, que a recepção das mensagens contidas em um filme não ocorre de maneira uniforme por todos os seus espectadores, o que certamente varia de acordo com sua cultura, sua idade, sua escolaridade e seu desenvolvimento cognitivo, dentre outros fatores.

Apesar disso, segundo depoimento do próprio autor do filme, se - receptor não possuir as informações para decifrar a mensagem, pelo menos ele se diverte e de alguma forma retém algo para si. Nesse sentido, não importa muito se todos compreendem o filme da mesma forma, mas sim o que cada espectador consegue apreender da obra.

Por outro lado, no entanto, o fato de um filme como Meow! permitir diversas interpretações por parte dos espectadores faz com que se ampliem as possibilidades de sua utilização como um texto não-escolar(10) também em sala de aula, ao mesmo tempo em que se exige do professor uma postura de mediador, no sentido de orientar os temas identificados por seus alunos. Essa constatação, por si só, abre um vasto campo de investigação das metáforas na área da educação.

Finalmente, vale ressaltar que vivemos numa época em que os veículos de comunicação assumem constantemente novas formas, com as quais temos que aprender a lidar. Nesse contexto, a metáfora apresenta-se como um importante elo entre os diversos meios porque não é intrínseca à tecnologia por onde é veiculada, mas à própria natureza humana.

Agradecimentos: os autores agradecem aos componentes do Grupo de Estudos de Metáforas e Analogias na Tecnologia, na Educação e na Ciência (GEMATEC) do CEFET-MG, e ao professor Ewaldo Mello de Carvalho, por suas valiosas contribuições.

\section{Abstract}

This article aims at presenting intentions and meanings attributed by Marcos Magalhães to the Meow! film. Through a semi-structured interview, the intentions and meanings attributed by the producer, to each scene or character, had been registered. The results had been analyzed and discussed having as theoretical support the proposals of Lakoff \& Johnson (2002), amongst others. The conclusion is that the author selects some aspects of our cultural experiences, and at the same time do not consider others, so, 
this makes the film a vehicle for a metaphoric reality. In this sense, the metaphor is presented as a resource of extreme importance for the artistic expression of Marcos Magalhães, which through the film, shows his vision of the world and his ideological political position.

Key-words: metaphors, analogies, cinematographic animation.

\section{Notas :}

(1) LAKOFF \& JOHNSON, 2002.

(2) Disponível no site Porta Curtas Petrobrás:

www.portacurtas.com.br/filme_abre_pop.asp?cod=811\&exib=2673

(4) LAKOFF \& JOHNSON, 2002, p. 208.

(5) NAGEM et al., 2001.

(6) LAKOFF \& JOHNSON, 2002. p. 168.

(7) SARTRE, 1996. p. 37.

(8) SARTRE, 1996. p. 34 .

(9) DELEUZE, 1990. p. 193.

(10) O termo é apresentado e discutido por diversos autores no livro organizado por CITELLI, 2002 .

\section{Bibliografia :}

CITELLI, Adilson Odair. Escola e Meios de Massa. In: ensinar com textos não escolares. São Paulo: Editora Cortez, 2002.

DAGNER, Zr. Rewiew of studies on the effectiveness of instructional analogies in Science Education. Science Education, v.79, n.3, 1995.

DELEUZE, Gilles. A Imagem-tempo. $1^{\text {a }}$ ed. São Paulo: Editora Brasiliense, 1990 .

GINo, Maurício Silva. A expressão e recepção do pensamento analógico/metafórico por meio da animação cinematográfica. Belo Horizonte: Centro Federal de Educação Tecnológica - CEFET/MG. Dissertação (Mestrado em Tecnologia), 2003 .

LAKOFF, George; JHONSON. Metáforas da vida cotidiana. Campinas: EDUC Editora da PUC/SP Mercado das Letras, 2002.

NAGEM, Ronaldo Luiz; CARVALHAES, Dulcinéia de Oliveira; Dias, Jully Ane Yamauchi Texeira. Uma Proposta de Metodologia de Ensino com Analogias. Revista Portuguesa de Educação, v. 14, n.1, 2001.

SARTRE, Jean-Paul. O Imaginário. São Paulo: Ática, 1996. 
TREAGUST, Thiele. Analogies in chemistry textebooks. International Journal of Science Education. v. 17, n.6. 1995.

WINNER, E.; GARDNER, H. Metaphor and irony: two levels of understanding. In: ORTONI, A. $2^{\text {a }}$ ed. Metaphor and thought. $2^{\text {a }}$ ed. Cambridge: Cambridge University Press, 1995 .

\section{FILMOGRAFIA}

MEOW. Direção: Marcos Magalhães. Rio de Janeiro: FUNART/CT Av., 1981.1 fita de vídeo (38 min.), VHS, son., color. 